\title{
Design and SAR Analysis of Wearable Antenna on Various Parts of Human Body, Using Conventional and Artificial Ground Planes
}

\author{
Usman Ali*, Sadiq Ullah ${ }^{\dagger}$, Jalal Khan*, Muhammad Shafi**, Babar Kamal*, Abdul Basir*, \\ James A Flint** and Rob D. Seager**
}

\begin{abstract}
This paper presents design and specific absorption rate analysis of a $2.4 \mathrm{GHz}$ wearable patch antenna on a conventional and electromagnetic bandgap (EBG) ground planes, under normal and bent conditions. Wearable materials are used in the design of the antenna and EBG surfaces. A woven fabric (Zelt) is used as a conductive material and a $3 \mathrm{~mm}$ thicker Wash Cotton is used as a substrate. The dielectric constant and tangent loss of the substrate are 1.51 and 0.02 respectively. The volume of the proposed antenna is $113 \times 96.4 \times 3 \mathrm{~mm}^{3}$. The metamaterial surface is used as a high impedance surface which shields the body from the hazards of electromagnetic radiations to reduce the Specific Absorption Rate (SAR). For on-body analysis a three layer model (containing skin, fats and muscles) of human arm is used. Antenna employing the EBG ground plane gives safe value of SAR (i.e. $1.77 \mathrm{~W} / \mathrm{kg}<2 \mathrm{~W} / \mathrm{kg}$ ), when worn on human arm. This value is obtained using the safe limit of $2 \mathrm{~W} / \mathrm{kg}$, averaged over $10 \mathrm{~g}$ of tissue, specified by the International Commission of Non Ionization Radiation Protection (ICNIRP). The SAR is reduced by $83.82 \%$ as compare to the conventional antenna ( 8.16 $\mathrm{W} / \mathrm{kg}>2 \mathrm{~W} / \mathrm{kg}$ ). The efficiency of the EBG based antenna is improved from 52 to $74 \%$, relative to the conventional counterpart. The proposed antenna can be used in wearable electronics and smart clothing.
\end{abstract}

Keywords: Wearable, Metamaterial, Specific absorption rate, Electromagnetic bandgap

\section{Introduction}

Antenna is the most vital component in wireless communication system design. The rapid development in mobile communication systems particularly Body Area Networks (BANs) and Personal Area Networks (PANs) demands for efficient antenna design [1]. These sensors employees various sensors which are fixed on the cloths, directly attached to human body or even implanted inside it. Another potential application of wearable antenna is in Body-Centric Wireless Communications (BCWCs) which is used in health monitoring, military purposes, and security applications [2]. Wearable systems are capable of remote patient monitoring which helps the doctors in diagnoses and control of the disease while working from home or clinic [3].

Wearable antennas have the requirement of being flexible and conformable to human body without disturbing his usual actions. In the literature, most of the researchers have proposed microstrip patch antennas the most suitable

$\dagger$ Corresponding Author: Dept. of Telecommunication Engineering, University of Engineering \& Technology, Peshawar, Pakistan. (sadiqullah@uetpeshawar.edu.pk)

* Dept. of Telecommunication Engineering, University of Engineering \& Technology, Peshawar, Pakistan. (usman_ali@uetpeshawar.edu.pk)

** School of Mechanical, Electrical and Manufacturing Engineering, Loughborough University, United Kingdom. (j.a.flint@lboro.ac.uk)

*** Dept. of Computer Science, Islamic University Madinah, Saudi Arabia. (muhammad.shafi@gmail.com)

Received: May 23, 2016; Accepted: October 24, 2016 candidate for wearable applications due to its characteristics of being low profile, conformal and inexpensive [4].

Majority of wearable antennas are based on textilematerials such as cotton, fabric, felt or jeans [5]. However other textiles such as wash cotton, curtain cotton, polyester, polycot, jean cotton [6], denim jeans [7], felt material [8], Tween, panama, moleskin, fleece, Perspex [9], Velcro [10], silk and nylon, are also used as a substrate materials. The textile material is low-loss, inexpensive and easily available in the market. Electro-textiles (e-textiles) are used as conductive fabric in the design of the radiating element and ground plane of the wearable antenna. These etextiles have the characteristics of a metal but are in the form of fabric [11]. These conductive fabrics must satisfy the requirements of high conductivity- low resistivity (less than $1 \mathrm{ohm} / \mathrm{sq}$.), enough flexibility to be worn pleasantly and should be homogenous and elastic in nature. In the literature mainly four types of conducting textiles materials are considered, namely, Shieldit, Flectron, Pure Copper Polyester Taffeta and Zelt [12]. The Zelt is a nylon based material plated with copper and tin, which is relatively a better choice due to its lower surface resistivity $(<0.01$ $\mathrm{ohm} / \mathrm{sq}$.) and higher conductivity of $1 \mathrm{e}+006 \mathrm{~S} / \mathrm{m}$. Therefore Zelt is used as a conducting fabric in the design of the proposed antenna and EBG surface in this paper.

Besides material selection, bending, crumpling, stretching and folding consequences due to the presence of human 
body, the design of wearable antenna is a challenging task. Wearable antennas operate in close proximity of human body, which has a high dielectric constant and conductivity. The presence of this high permittivity body results in frequency detuning of the antenna from the resonant point. When these antennas are used in close proximity to human body, the side and backlobe radiations get penetrated and absorbed in body tissues. The absorption of power per unit mass of human body is evaluated by a term known as the Specific Absorption Rate (SAR).

Specific Absorption Rate $(S A R)$ is a measure of electromagnetic wave penetration in human body tissues [13]. The standard unit for SAR is watt per kilogram $(\mathrm{W} / \mathrm{kg})$. SAR can also be considered as an "absorbed rate" which is directly related to the electric fields at a point i.e.

$$
S A R=\frac{\sigma|E|^{2}}{\rho}\left(\frac{W}{K g}\right)
$$

Where, $\sigma$, is the conductivity of the tissue $(\mathrm{S} / \mathrm{m}), \rho$, mass density of tissue $\left(\mathrm{Kg} / \mathrm{m}^{3}\right)$ and $E$, is the root mean square (r.m.s) of electric field strength $(\mathrm{V} / \mathrm{m})$. SAR can also be calculated as rate of temperature rise at a given point, used in some basic research [14]. The SAR limits for mobile phones and similar devices are regularized and specified internationally. The maximum safe limit of SAR specified by the US standard is $1.6 \mathrm{~W} / \mathrm{kg}$ for $1 \mathrm{~g}$ of tissue. The International Commission of Non Ionization Radiation Protection (ICNIRP) for Europe has set maximum level of SAR as $2 \mathrm{~W} / \mathrm{kg}$ for any $10 \mathrm{~g}$ of tissue [15].

Specific Absorption Rate $(S A R)$ can also be defined as, the time derivative of incremental energy (dW) dissipated in an incremental mass $(\mathrm{dm})$ in a volume $(\mathrm{dV})$ of a given density $(\rho)$, which is described by [16].

$$
\begin{gathered}
S A R=\frac{d}{d t}\left(\frac{d W}{d m}\right)=>\frac{d}{d t}\left(\frac{d W}{\rho(d V)}\right) \\
S A R=\frac{1}{\rho}\left(\frac{d W}{d t}\right)
\end{gathered}
$$

Where, $d W$, is the energy absorbed, $\mathrm{dm}$, the mass and $d V$, is the volume element.

Wearable microstrip patch antennas show relatively higher SAR in human body, due to their unwanted radiations towards human body which needs to be controlled. Therefore, researchers worked on reducing the $S A R$ of patch antennas by using a ferrite sheet [17] or Perfect Electric Conductor (PEC) reflector [18] as a shielding layer between the antenna and human body.

Recently, metamaterial surfaces have motivated antenna engineers due to their unique electromagnetic properties and innovative applications [19]. These surfaces are artificially constructed surfaces having electromagnetic properties that does not exist in nature. Metamaterial based
Electromagnetic Band Gap (EBG) surfaces restricts the propagation of surface waves within a specific frequency band (known as band gap) and therefore reduce the level of unwanted backlobe radiations towards the human body. Hence when these EBG surfaces are used as a ground planes in the design of wearable antennas, they limit the value of SAR to the safe level [20]. In this paper, it is found that radiation characteristics of the conventional antenna are highly affected in the presence of human body. Therefore the electromagnetic behavior of the proposed wearable antenna is analyzed and the importance of metamaterial surfaces is clearly demonstrated in this work.

The rest of the paper is organized as follows: The design procedure and general layout of the proposed conventional patch antenna is presented in section 2. In section 3, the antenna is backed by a metamaterial surface and its characteristics are compared with the conventional antenna. Design and modeling of human body phantom (flat, arm) is explained in section 4. Specific Absorption Rate (SAR) analysis of the $2.4 \mathrm{GHz}$ antenna on flat body phantom and arm has been presented in section 5. Section 6 concludes the paper and gives directions for future work. All the simulations are carried out using FDTD technique implemented in CST Microwave Studio.

\section{Conventional Patch Antenna Worn on Flat Section of Human Body}

In this section the design of conventional antenna alone and in close proximity of human body has been discussed.

\subsection{Design}

In this paper, we proposed a rectangular microstrip patch antenna for wearable applications shown in Fig. 1. The top layer of the proposed antenna is made of $0.06 \mathrm{~mm}$ thicker conducting e-textile (Zelt). The length $(L)$ and width $(W)$ of this radiating layer are 48.2 and $56.5 \mathrm{~mm}$ respectively. The radiating layer is backed by $3 \mathrm{~mm}$ thicker wash cotton based dielectric substrate layer of length $\left(L_{g}=96.4 \mathrm{~mm}\right)$ and width $\left(W_{g}=113 \mathrm{~mm}\right)$. The dielectric constant $\left(\varepsilon_{r}\right)$ and tangent loss $(\delta)$ of wash cotton are 1.51 and 0.02 respectively. The bottom layer is a finite $0.06 \mathrm{~mm}$ thicker conducting (Zelt)

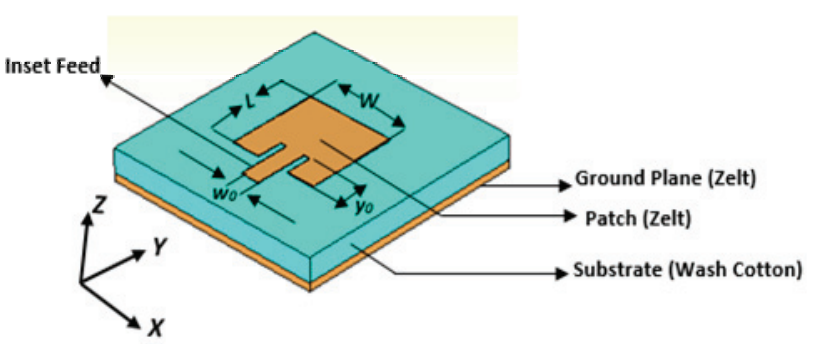

Fig. 1. Geometry of traditional patch antenna on wearable substrate 
ground plane, having identical dimensions (length and width) as that of the substrate. Microstrip inset feeding is used for the excitation of the antenna. The inset feed depth $\left(y_{o}\right)$ and width $\left(w_{o}\right)$ are $17.13 \mathrm{~mm}$ and $11 \mathrm{~mm}$ respectively. The dimensions of the patch antenna as well as feed line are found using the standard transmission line theory [21].

$$
\begin{gathered}
W=\frac{C}{\left(2 f_{r}\right) \sqrt{\frac{2}{\varepsilon_{r}+1}}} \\
L=\frac{0.492}{f_{r} \sqrt{\varepsilon_{r}}}
\end{gathered}
$$

Using the model expansion analysis, the reduced inset feed point impedance is given approximately by:

$$
\begin{gathered}
R_{\text {in }}\left(y=y_{0}\right)=\frac{1}{2(G 1 \pm G 12} \cos 2\left(\pi \times \frac{y_{0}}{L}\right) \\
R_{\text {in }}(y=0)=\frac{1}{2(G 1 \pm G 12)} \\
R_{\text {in }}\left(y=y_{0}\right)=R_{\text {in }}(y=0) \cos 2\left(\pi \times \frac{y_{0}}{L}\right)
\end{gathered}
$$

The resonant input impedance depends upon the inset feed-point distance $y_{o}$. As $y_{o}$ increases, the input impedance decreases. This mechanism is very effective for small values of characteristic impedance of the order of $50 \mathrm{ohms}$.

\subsection{Antenna behavior on Flat-Body Phantom}

Due to the heterogeneous and lossy nature of human body, the performance of an antenna is affected when placed in close proximity of human body. Therefore the performance of antenna is first evaluated in free space and then tested for on-body flat section. For this purpose a three layered body phantom is designed in CST Microwave studio that consists of muscle, fat and skin as shown in Fig. 2 . The average permittivity and conductivity of these layers at $2.4 \mathrm{GHz}$ are: Muscle $\left(\varepsilon_{r}=52.79 ; \sigma=1.705\right)$, Fat $\left(\varepsilon_{r}=5.28\right.$; $\sigma=0.1)$ and Skin $\left(\varepsilon_{r}=31.29 ; \sigma=5.0138\right)$ [22]. The thickness of Muscle, Fat and Skin layers are $23 \mathrm{~mm}, 8 \mathrm{~mm}$ and $2 \mathrm{~mm}$

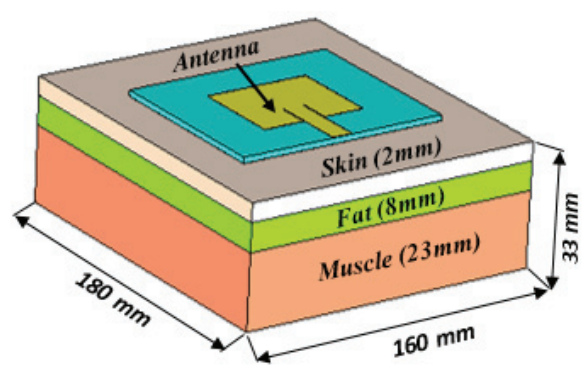

Fig. 2. Patch antenna mounted on the flat body Phantom of human body respectively. Due to the simulation complexity the amount of water content in these layers has not been considered. The proposed $2.4 \mathrm{GHz}$ wearable antenna is fixed on a 180 $\mathrm{mm} \times 160 \mathrm{~mm}$ flat body-phantom, in order to study its radiation characteristics in close proximity to human body.

Various field parameters i.e. gain, return loss and radiation pattern of the proposed antenna in flat state, are compared under ON and OFF body conditions. The return loss of the microstrip patch antenna is -36.67 and $-38.76 \mathrm{~dB}$ in OFF and ON body conditions respectively shown in Fig. 3.

The antenna gives an acceptable bandwidth (99.6 MHz) suitable for ISM band applications in both states. The return loss of the patch antenna in the ON-body state is shifted slightly towards the right side of the $2.4 \mathrm{GHz}$ resonance frequency. The detuning of frequency is due to the high dielectric constant property of various layers of human body.

The $E$-plane radiation patterns of the conventional patch antenna and antenna mounted on Flat Body phantom are compared in Fig. 4. The radiation pattern of both the antennas are adequately consistent at the desired resonance frequency. It is clear from Fig. 4 that for the antenna worn on the flat-body phantom, the peak value of gain decreased by $(0.05 \mathrm{~dB})$, while directivity increased by $(0.064 \mathrm{dBi})$.

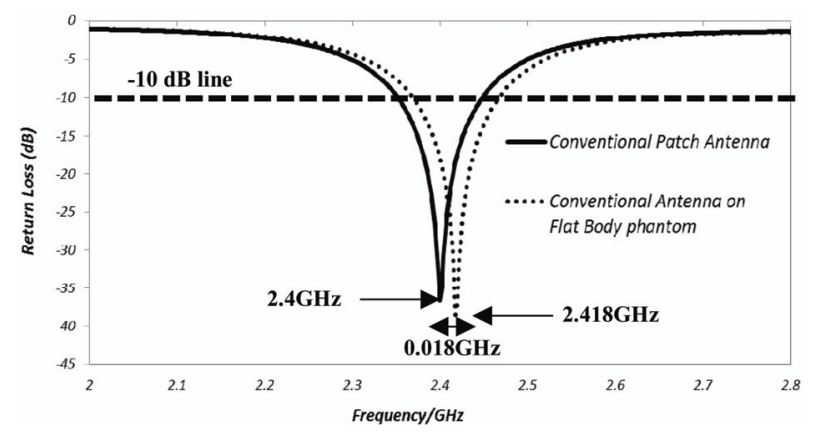

Fig. 3. Return loss of conventional patch antenna and antenna on flat body Phantom

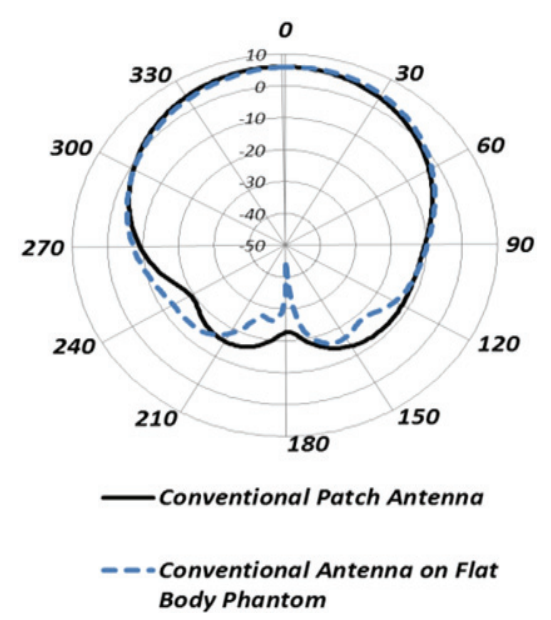

Fig. 4. Far field gain pattern of conventional antenna and antenna on flat body phantom 
Therefore the total radiated efficiency of antenna on flatbody phantom decreases by $(1 \%)$. This is due to the higher conductivity of the outer most layer skin. Moreover, the antenna worn on the flat-body phantom radiate with broader beam width $(81.3 \mathrm{deg})$, compared to conventional antenna $(65.6 \mathrm{deg})$.

\section{Wearable Antenna with Metamaterial Surface}

This section presents the design of HIS/EBG surfaces at $2.4 \mathrm{GHz}$. These surfaces will be used as a ground plane to improve and compare the performance of the antenna under both $\mathrm{ON}$ and OFF body conditions.

\subsection{Designing of metamaterial surfaces}

To design a mushroom type EBG, which provide inphase reflection and also possess the property of surface waves suppression. These surfaces exhibits the property of a High Impedance Surface (HIS) within a certain frequency band gap in which surface waves propagation is highly restricted [23]. These surfaces have been utilized in antenna designs for reducing the radiations in backward direction, to increase the gain and radiation efficiency along the boresight direction.

In this section the design and characterization of a mushroom-like EBG structure is presented. It consists of a metallic patch and a cylindrical via, passing through the substrate, to connect the patch to the ground of the EBG unit cell shown in Fig. 5. Wash cotton is used for the substrate and Zelt material is modeled as a conducting material for the top patch and the bottom ground plane.

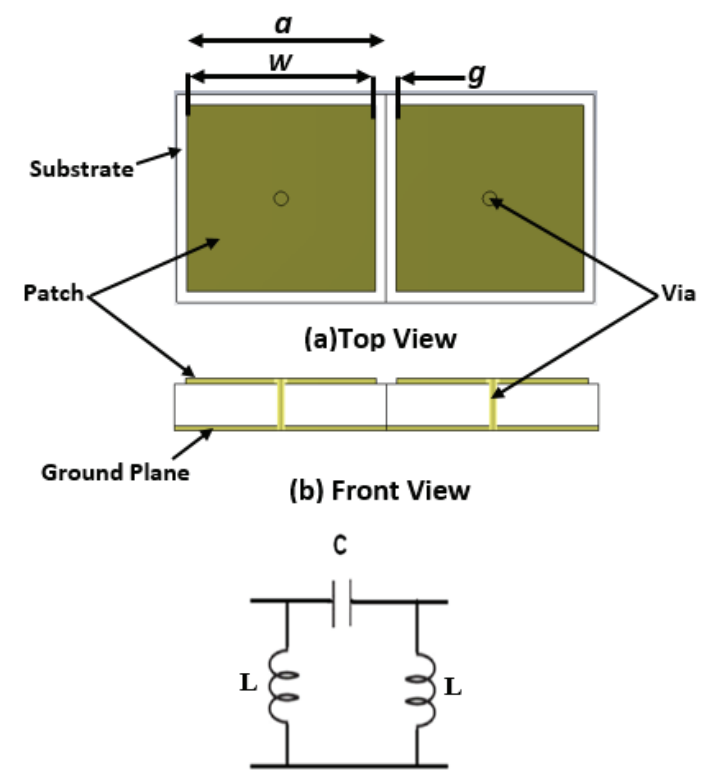

(c) LC-resonant Circuit

Fig. 5. Unit-Cell geometry: (a) Top View; (b) Front View; (c) $L C$-resonant circuit
The dimensions of EBG unit cell are found using the wellknown Sievenpiper's surface design equations [24].

The above surface acts like a $2 \mathrm{D}$ parallel $L C$-resonant circuit, the capacitance and inductance are the key elements of the circuit. The resonance frequency and in-phase bandwidth of the EBG depends upon the inductance $L$ and capacitance $C$, which further depends upon the geometry and dimension of the unit cell [23]. The resonant frequency of EBG surface is given by:

$$
f_{r}=\frac{1}{2 \pi \sqrt{L C}}
$$

Where, $C$ is the capacitance due to fringing between the neighboring unit cells, given by:

$$
C=\frac{w \varepsilon_{0\left(1+\varepsilon_{r}\right)}}{\pi} \cosh ^{-1}\left(\frac{w+g}{g}\right)
$$

Where, $\varepsilon_{0}$ is permittivity of vacuum, $w$, width of the unit cell and $g$, gap between neighboring unit cells. The inductance $L$ is directly dependent on length of metal via (or thickness $t$ of the substrate)

$$
L=\mu_{0} \mu_{r} t
$$

For the desired frequency of $2.4 \mathrm{GHz}$ the optimized dimensions of unit-cells shown in Fig. 5 are: $w=$ $0.323 \lambda_{2.4 \mathrm{GHz}}, \quad g=0.018 \lambda_{2.4 \mathrm{GHz}}$, where $\lambda 2.4 \mathrm{GHz}$ is free space wavelength at $2.4 \mathrm{GHz}$, via (radius) $=0.004 \lambda_{2.4 \mathrm{GHz}}$. Therefore, this yields the following:

$$
\begin{aligned}
& L=w=40.4 \mathrm{~mm} ; g=2.2 \mathrm{~mm} ; a=w+g=42.6 \mathrm{~mm} ; \\
& \mathcal{E}_{r}=1.51 ; h=3 \mathrm{~mm}
\end{aligned}
$$

The extent to which HIS surface suppress surface wave can be measured by various means, i.e. dispersion diagram or a transmission line method. In this paper a suspended transmission line method has been taken in to consideration. In this method a conducting metal strip is mounted on top of EBG surface and excited such that one port acts as a source and the other as a matched load. The simulation

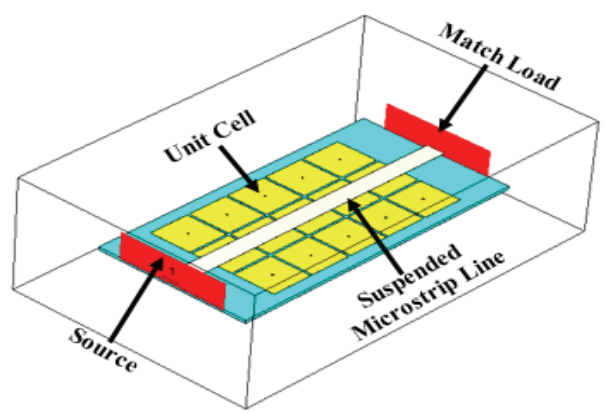

Fig. 6. Suspended Strip line model for surface wave suppression characterization 
setup for surface wave characterization is shown in Fig. 6.

The simulated reflection phase, impedance and scattering $(S)$ parameters of the proposed EBG surface are shown in Fig. 7. The surface gives in-phase $\left(0^{\circ}\right)$ reflection at 2.4 $\mathrm{GHz}$ and behaves like a Perfect Magnetic Conductor (PMC) at this frequency as shown in Fig. 7(a). The simulated reflection phase varies from $+90^{\circ}$ to $-90^{\circ}$ within the $2.2 \mathrm{GHz}$ to $2.54 \mathrm{GHz}$ band. Within this band the surface behaves as an Artificial Magnetic Conductor (AMC). The surface acts as a high impedance $(\approx 1.2 \mathrm{k} \Omega)$ surface within the 2.35 to $2.5 \mathrm{GHz}$ frequency band (Fig. $7 \mathrm{a}$ ). The surface offers a maximum impedance of $\approx 2 \mathrm{k} \Omega$ at the resonant frequency $(2.4 \mathrm{GHz})$. The transmission coefficient $\left(S_{2 I}\right)$ is minimum $(<-40 \mathrm{~dB})$ within a specific band of frequencies (from 2.34 to $2.57 \mathrm{GHz}$ ) centered at $2.4 \mathrm{GHz}$ (Fig.7b). Within this band the transmission of surface waves is kept to the minimum level. This band of frequencies within which the surface acts as a high impedance surface to suppress the surface waves, is called surface wave Bandgap of the EBG. Outside this band it is working like an ordinary Perfect Electric Conductor (PEC).

Since the proposed antenna operates in this band, and also suffer from the drawback of very low efficiency due to

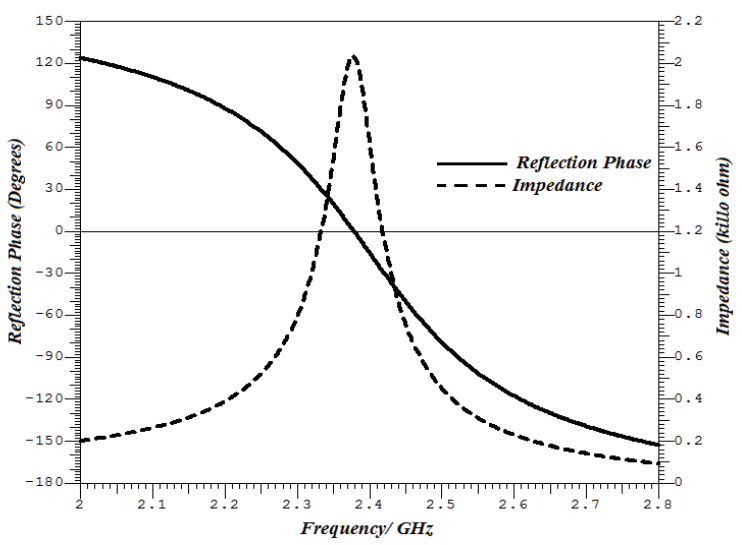

(a)

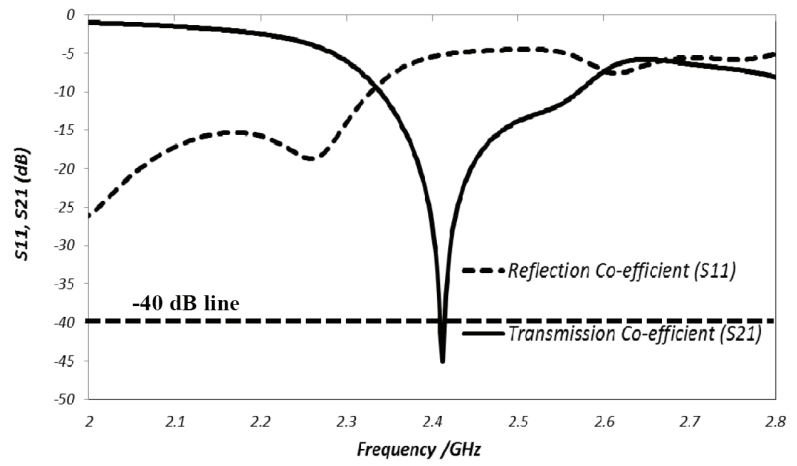

(b)

Fig. 7. Unit cell characterization: (a) Simulated reflection phase and surface impedance; (b) Simulated scattering $\left.\left(S_{11}, S_{21}\right)\right)$ parameter of EBG showing band gap behavior surface waves propagation within the substrate, therefore replacing the conventional ground plane with this EBG ground plane will help in enhancing the gain and efficiency of this antenna.

\subsection{Integration of conventional antenna and EBG/ HIS Surface}

In this section the conventional wearable patch antenna is integrated with EBG surface. For this purpose an array of $5 \times 5 \mathrm{EBG} / \mathrm{HIS}$ has been prepared as shown in Fig. 8 . The performance of the antenna is analyzed under normal and bent conditions, in the presence and absence of human body.

The return loss of the conventional antenna and metamaterial inspired antenna is compared in Fig. 9. It is observed that return loss of metamaterial inspired antenna has improved to $-44 \mathrm{~dB}$ at $2.4 \mathrm{GHz}$, resulting in $2.3 \%$

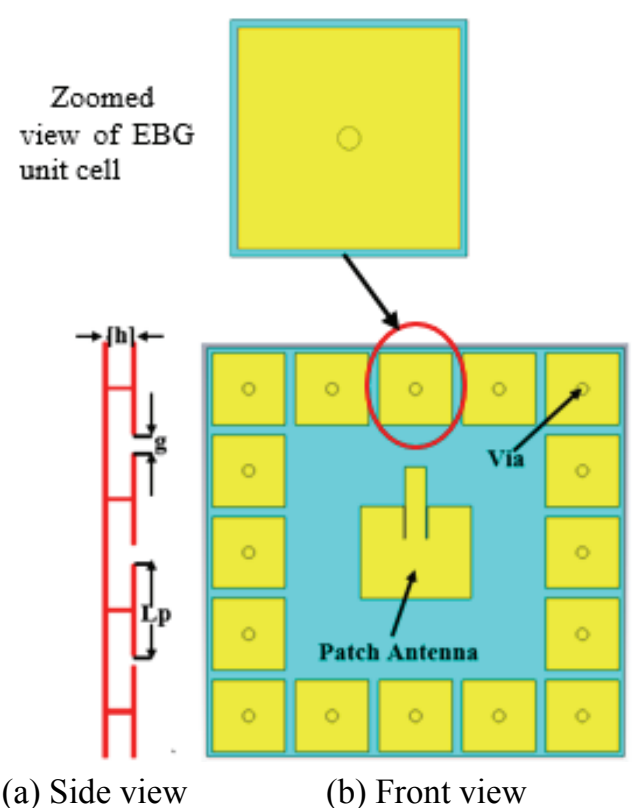

Fig. 8. Metamaterial based microstrip patch antenna: (a) Side view; (b) Front view

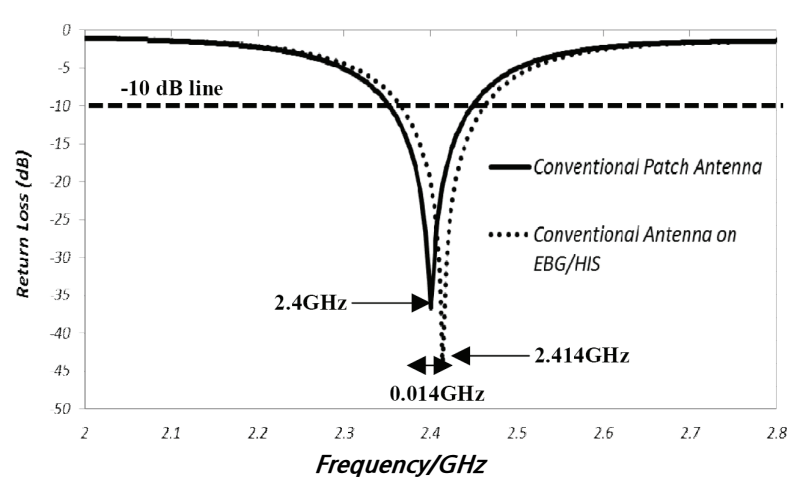

Fig. 9. Return loss comparison of conventional antenna and antenna on EBG/HIS surface 
Table 1. Summary of results (Conventional Vs EBG in Flat condition)

\begin{tabular}{c|c|c}
\hline Parameters/ Type of Antenna & Conventional & Mushroom EBG \\
\hline Frequency (GHz) & 2.4 & 2.414 \\
\hline Return Loss (dB) & -36.67 & -44.618 \\
\hline Gain (dB) & 6.091 & 7.316 \\
\hline Directivity (dBi) & 8.849 & 8.618 \\
\hline Bandwidth (MHz) & 97.4 & 99.7 \\
\hline Efficiency (\%age) & 52.8 & 74.04 \\
\hline Beamwidth (Deg) & 65.6 & 95.7 \\
\hline Input impedance (Real Part) & 49.58 & 49.91
\end{tabular}

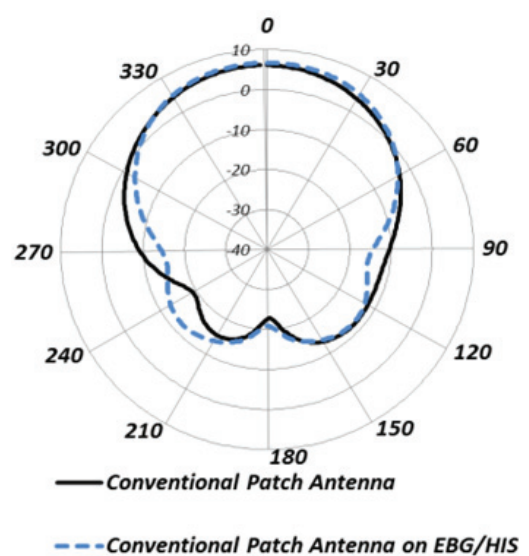

Fig. 10. Radiation pattern comparison of Conventional and EBG/HIS based antenna

increase in $-10 \mathrm{~dB}$ bandwidth, relative to conventional patch antenna. The overall performance, particularly efficiency and beamwidth of the EBG based antenna is relatively enhanced by $22 \%$ and $30 \%$, respectively tabulated in Table 1.

At $2.4 \mathrm{GHz}$, the simulated gain of the conventional antenna is $(6.091 \mathrm{~dB})$ as shown in Fig. 10. Due to the high impedance nature of the EBG ground plane, the gain of the proposed antenna is improved to $(7.316 \mathrm{~dB})$. In addition the radiation efficiency of the EBG based antenna is increased by $(22 \%)$. Both the antennas have a directional radiation pattern, normal to the plane of the radiating patch. The EBG based antenna also radiate in a broader angular span (i.e. beamwidth $=95.7 \mathrm{deg}$ ) as compared to conventional antenna $(65.6 \mathrm{deg})$.

\section{Human Phantom Modeling and Bending of Antenna}

In a practical on-body application, the antenna is presumed to be printed on the garments, and then it is exposed to bending. For this purpose a simple model (phantom) of human arm of $45 \mathrm{~mm}$ radius is proposed in this paper. The arm phantom is modelled using CST MWS and it consists of four layers, i.e. skin, fat, muscle and bone. The materials and design parameters of the arm are the
Table 2. Properties of human body tissues

\begin{tabular}{c|c|c|c|c}
\hline Tissue & $\begin{array}{c}\text { Permittivity } \\
\left(\varepsilon_{r}\right)\end{array}$ & $\begin{array}{c}\text { Conductivity } \\
(\mathrm{S} / \mathrm{m})\end{array}$ & $\begin{array}{c}\text { Loss } \\
\text { Tangent }\end{array}$ & $\begin{array}{c}\text { Density } \\
\left(\mathrm{Kg} / \mathrm{m}^{3}\right)\end{array}$ \\
\hline Skin & 31.29 & 5.0138 & 0.2835 & 1100 \\
\hline Fat & 5.28 & 0.1 & 0.19382 & 1100 \\
\hline Muscle & 52.79 & 1.705 & 0.24191 & 1060 \\
\hline Bone & 12.661 & 3.8591 & 0.25244 & 1850 \\
\hline
\end{tabular}

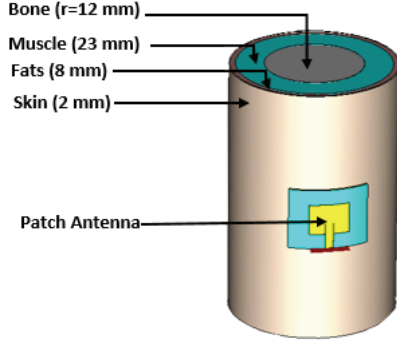

(a)

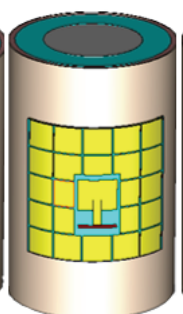

(b)

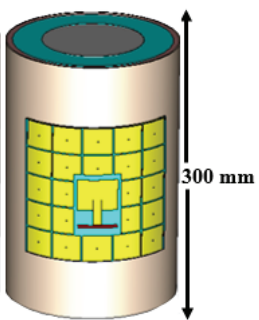

(c)
Fig. 11. Antenna bent around a four layered model of human arm of radius $\mathrm{r}=45 \mathrm{~mm}$ : (a) Conventional; (b) with EBG (via less); (c) with EBG (via)

same as described in [15]. The intrinsic properties of each layer are summarized in Table 2.

In this paper the effects of $E$-plane bending of the antennas are discussed in three stages:

1) First the $2.4 \mathrm{GHz}$ antenna is bent around the cylindrical arm phantom and then analyzed in free space in the absence of the arm. In other words the radius of the bent antenna is kept equal to the radius of the arm (i.e. 45 $\mathrm{mm}$ ) and its performance is gauged in free-space in the absence of the body.

2) The conventional $2.4 \mathrm{GHz}$ antenna is worn on human arm to investigate its performance (gain, directivity, efficiency and SAR) in close proximity to the lossy human body.

3) On-body analysis of the EBG backed $2.4 \mathrm{GHz}$ antenna in order to investigate the reduction in $S A R$ due to the high-impedance nature of the EBG ground plane.

The concept of bending the proposed antenna using conventional and EBG ground planes is illustrated in Fig. 11. The effects of bending and human body on the performance of the antenna are discussed in the following paragraphs:

\subsection{Off-body analysis}

In this segment, the bent antenna is analyzed and compared with the conventional antenna in the absence of human body using CST Microwave Studio.

\subsubsection{One-dimensional (1D) results}

Bending affects, the driving point impedance of the patch antenna, hence the resonant frequency is slightly shifted towards the left of $2.4 \mathrm{GHz}$ shown in Fig. 12. It is 
worth mentioning that the antenna retain its operation within the unlicensed ISM band irrespective of bending.

\subsubsection{Two-dimensional (2D) results}

The $E$-plane and $H$-plane simulated gain of both the antennas is compared in Fig. 13(a)-(b).

It is clearly shown that due to bending, the maximum gain of the conventional antenna, along the bore side

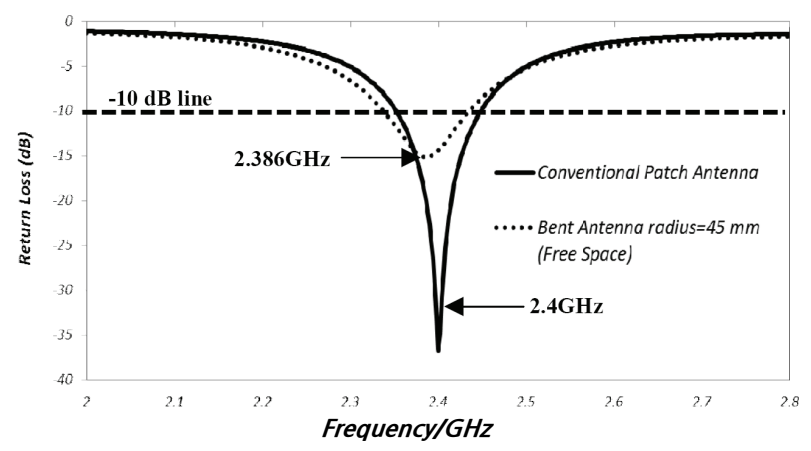

Fig. 12. Simulated return loss comparison of conventional antenna and bent antenna

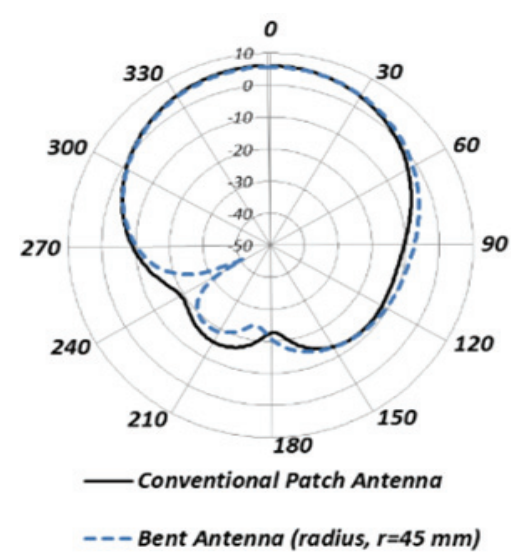

(a) E-Plane gain

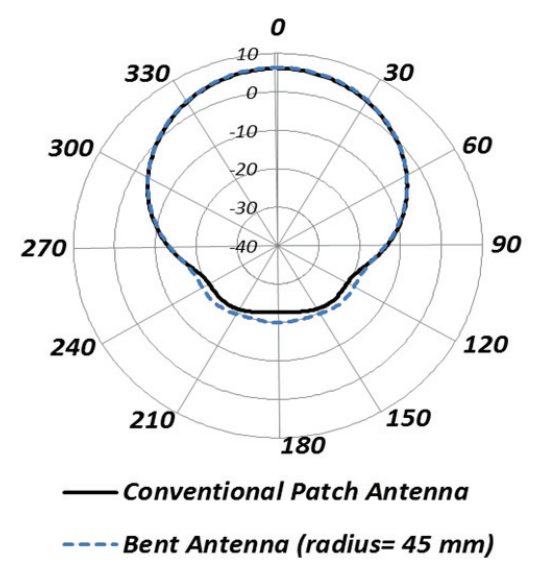

(b) H-Plane gain

Fig. 13. Gain patterns comparisons of conventional antenna under normal and bent conditions: (a) E-Plane; (b) H-Plane direction, is reduced (from $6.091 \mathrm{~dB}$ to $5.721 \mathrm{~dB}$ ). The conventional antenna (under flat or normal condition) shows lowest side lobe radiations $(-24.3 \mathrm{~dB})$ compared to the bent antenna $(-17.9 \mathrm{~dB})$. It is worth mentioning that the $-3 \mathrm{~dB}$ beamwidth of the bent conventional antenna grows up to $(77.8 \mathrm{deg})$ relative to the normal case $(65.6 \mathrm{deg})$. Alternatively, the antenna become less directive $(8.358$ $\mathrm{dBi}$ ), due to which it has the capability to detect a wider range of arrival. The $H$-plane gain pattern shows that the direction of the main lobe is shifted due to bending, from ( $0 \mathrm{deg}$ to $2 \mathrm{deg}$ ). In addition the $-3 \mathrm{~dB}$ beamwidth of the conventional antenna expands from (64.2 deg to $97.5 \mathrm{deg})$, for normal and bent conditions respectively.

\subsubsection{Three-dimensional results}

The 3D gain pattern, of antenna in normal and bent conditions are presented in Fig. 14(a) - (b). The maximum gain of the antenna in normal and bent scenarios is $(6.09$ $\mathrm{dB})$ and $(5.72 \mathrm{~dB})$ respectively which shows that bending causes reduction in boresight gain of the antenna.

\subsection{On-body analysis}

\subsection{1 $1 \mathrm{D}$ results}

The lossy nature of human body makes the antenna less efficient radiator due to impedance mismatch between the (a)

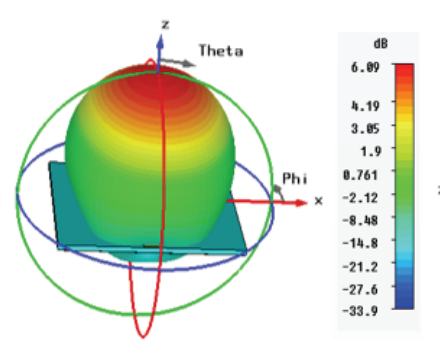

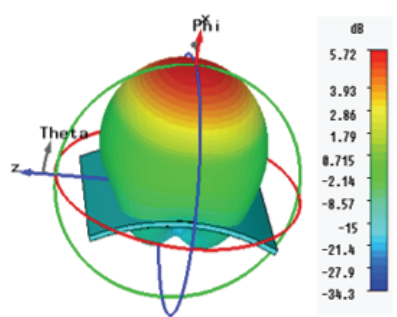

(b)
Fig. 14. 3D radiation pattern of (a) conventional antenna; (b) bent antenna

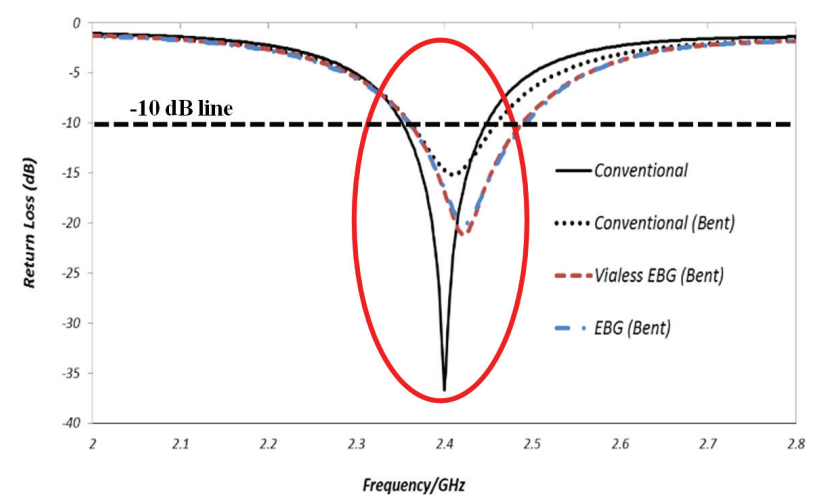

Fig. 15. On-body reflection coefficient comparison of conventional and bent antennas around human arm of $45 \mathrm{~mm}$ radius 


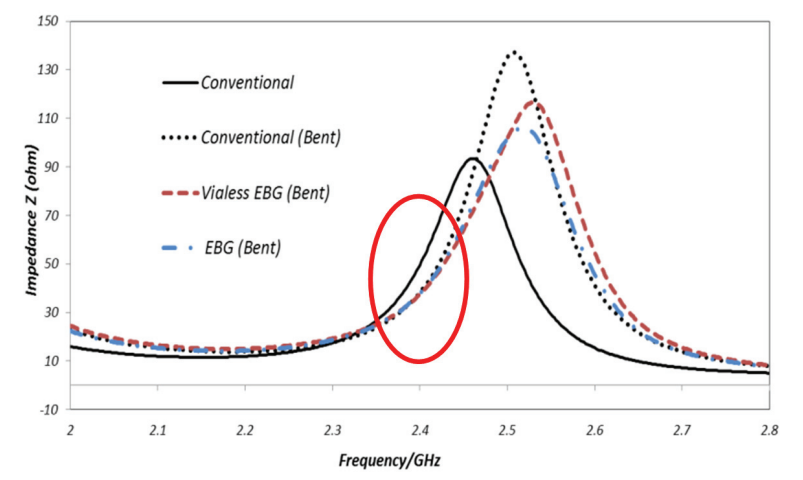

Fig. 16. An enlarged view of the Input Impedance on human body arm, we see that bending causes the impedance to decrease.

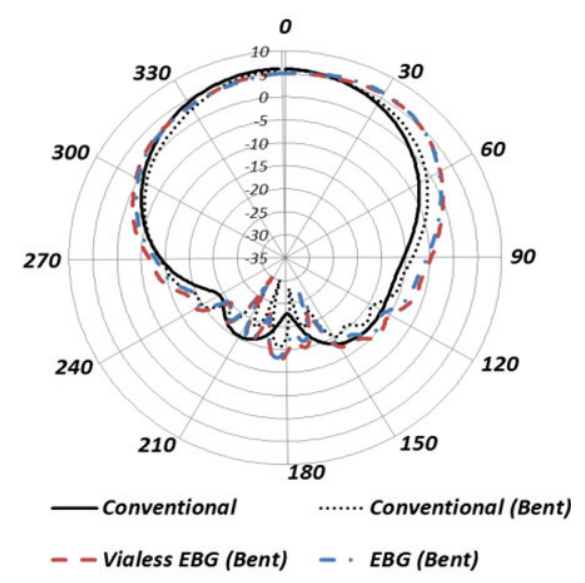

(a) E-Plan Gain

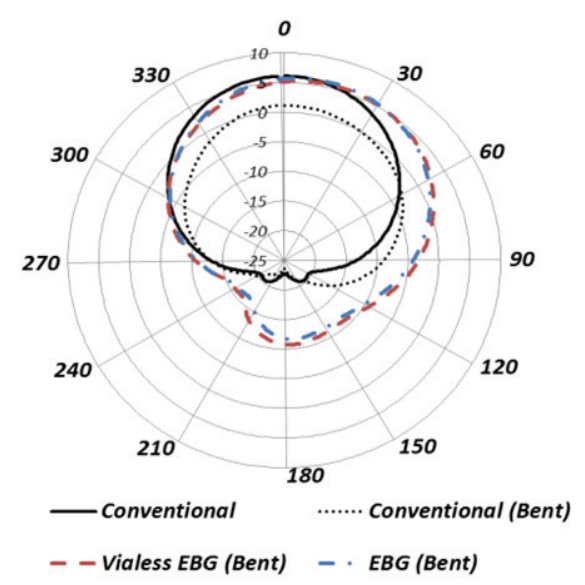

(b) H-Plane Gain

Fig. 17. On-body gain patterns comparison of conventional and bent antennas around human arm of $45 \mathrm{~mm}$ : (a) E-Plane; (b) H-Plane

antenna and transmission line. In this segment the return loss and input impedance of the EBG based antenna is analyzed in close proximity of human arm, and the results are compared with the conventional all-alone normal patch antenna. When the antennas are worn on the human body
Table 3. Gain and main lobe comparison of bent antenna in $E\left(\varphi=90^{\circ}\right)$ and $H\left(\varphi=0^{\circ}\right)$ planes

\begin{tabular}{c|c|c|c|c}
\hline \multirow{2}{*}{$\begin{array}{c}\text { Antenna/ } \\
\text { Geometry }\end{array}$} & \multicolumn{2}{|c|}{ Gain (dB) } & \multicolumn{2}{c}{ Main lobe direction (Deg) } \\
\cline { 2 - 5 } & E-Plane & H-Plane & E-Plane & H-Plane \\
\hline Conventional & 6.10 & 6.10 & 0.0 & 00 \\
\hline Conventional (Bent) & 5.90 & 4.9 & 0.0 & 2.0 \\
\hline Vialess EBG (Bent) & 5.99 & 5.6 & 30 & 16 \\
\hline EBG (Bent) & 6.29 & 6.0 & 28 & 12 \\
\hline
\end{tabular}

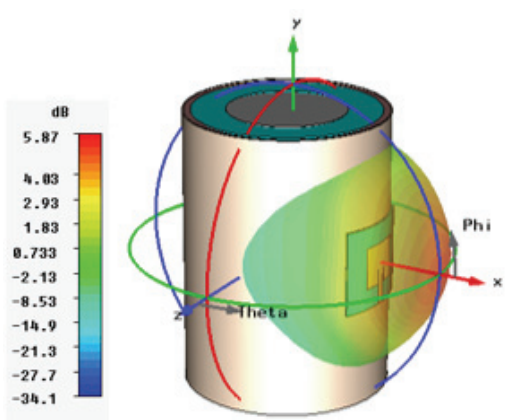

(a)

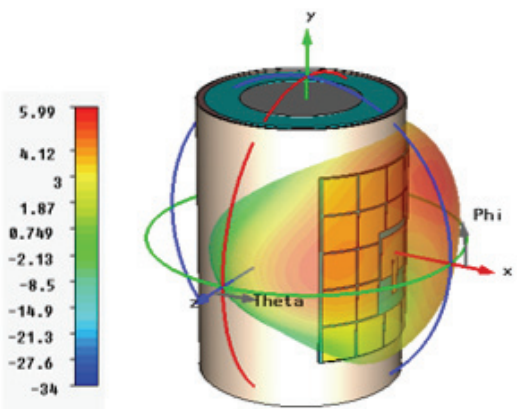

(b)

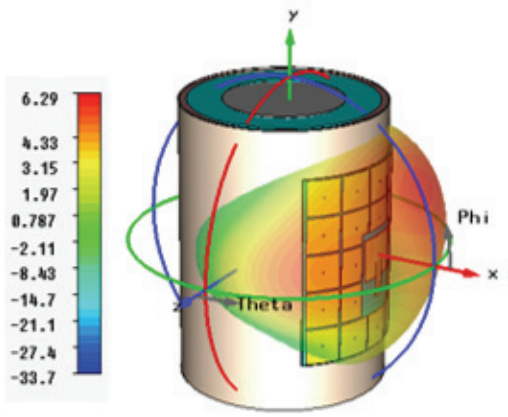

(c)

Fig. 18. Perspective view of 3D-gain pattern of the proposed $2.4 \mathrm{GHz}$ antenna under bent conditions: (a) conventional; (b) Vialess EBG; (c) EBG

(arm), bending results in reduction of the driving point impedance of the antenna, which causes slight detuning of the resonance frequency as well as a decline in return loss. It is worth noticing that, under bent conditions, the metamaterial inspired antenna has reasonably good return loss as compared to conventional antenna.

\subsubsection{D results}

The $E$-plane and $H$-plane simulated gains of the 
conventional and EBG based antennas are compared in Fig. 17(a) - (b) respectively. The antenna with the EBG ground plane shows satisfactory performance in terms of $\mathrm{E}$ and $\mathrm{H}-$ plane gain $(\geq 6 \mathrm{~dB})$, relative to the conventional and Vialess EBG antennas under bent scenarios.

The maximum gain and main lob direction for all configurations are summarized in Table 3, which shows that the EBG backed antenna retain fair gain under body worn conditions.

\subsection{3 $3 D$ results}

Fig. 18 illustrate the perspective view of 3D-gain pattern of the conventional antenna and metamaterial based antenna worn on human body arm of (radius $=45 \mathrm{~mm}$ ). The lossy human body acts as an absorber of the electromagnetic radiations hence reducing the peak gain of the antennas. It is important that the antennas, irrespective of the type of ground plane, give a fair gain $(>5.8 \mathrm{~dB})$, which is acceptable for on-body communication networks. Due to the high-impedance nature of the EBG (with Vias), the surface waves within the substrate are suppressed, which reduces the backward radiations, thereby minimalizing the specific absorption rate.

\section{Specific Absorption Rate (SAR) Analysis}

Specific Absorption Rate analysis of the $2.4 \mathrm{GHz}$ antenna on flat body phantom and arm has been presented in this section. Only E-plane bending was considered. The SAR analysis is carried out using CST Microwave Studio, using the IEEE C95.3 averaging method. SAR calculations have been carried out over 10 gram of tissue volume (ICNIRP, European standard). The safe level for the standard is 2 $\mathrm{W} / \mathrm{kg}$ for any 10 gram of tissue.

Human body is a chunk of highly conductive and dielectric material. When the conventional antenna is operated in close proximity of human body, it is detuned due to mismatch in impedance, and some portion of the available power is reflected backwards and absorbed in the body, which results in higher values of Specific Absorption Rate (SAR). Therefore, a high-impedance metamaterial surface has been proposed as an artificial ground plane to shield or isolate the human body from the adverse effects of backward radiations, which are responsible for an increase in the SAR.

Three geometries were considered in this section:

1) Conventional antenna on a $180 \mathrm{~mm} \times 160 \mathrm{~mm}$ rectangular flat body phantom,

2) Conventional antenna bent around human body arm (radius $=45 \mathrm{~mm}$ ) and

3) Metamaterial inspired antenna bent around human body arm (radius $=45 \mathrm{~mm}$ ).

The snap shots of the SAR and peak power loss density
Table 4. Summary of simulated SAR normalized to $0.5 \mathrm{~W}$ (r.m.s) at $2.4 \mathrm{GHz}$

\begin{tabular}{c|c|c|c}
\hline Antenna & Phantom & $\begin{array}{c}10 \mathrm{~g} \text { Peak } \\
\text { SAR } \\
(\mathrm{W} / \mathrm{kg})\end{array}$ & $\begin{array}{c}\text { Peak power } \\
\text { loss density } \\
\left(\mathrm{W} / \mathrm{m}^{3}\right)\end{array}$ \\
\hline Conventional & Flat & 0.036 & 23064 \\
\hline Conventional & $\begin{array}{c}\text { Human Body Arm } \\
\text { (radius=45mm) }\end{array}$ & 8.16 & 122000 \\
\hline $\begin{array}{c}\text { Metamaterial Based } \\
\text { (Without Vias) }\end{array}$ & $\begin{array}{c}\text { Human Body Arm } \\
\text { (radius=45mm) }\end{array}$ & 2.36 & 37613 \\
\hline $\begin{array}{c}\text { Metamaterial Based } \\
\text { (With Vias) }\end{array}$ & $\begin{array}{c}\text { Human Body Arm } \\
\text { (radius=45mm) }\end{array}$ & 1.77 & 31403 \\
\hline
\end{tabular}
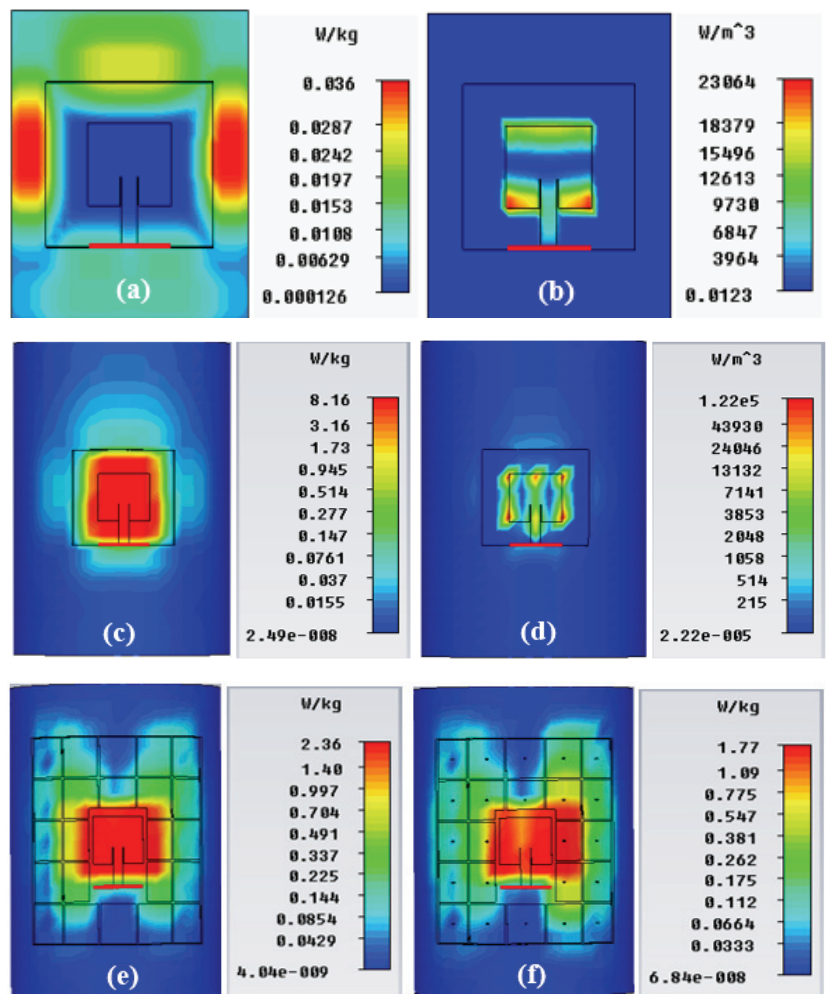

Fig. 19. Conventional antenna on flat phantom: (a) SAR; (b) power loss density; conventional antenna bent around human arm; (c) SAR; (d) Power loss density; SAR analysis of EBG based antenna bent around arm; (e) Without Vias; (f) With Vias

at $2.4 \mathrm{GHz}$ have been shown in Fig. 19. The simulated results are normalized to an R.M.S reference power of $0.5 \mathrm{~W}$ illustrated in Table 4.

It is clearly shown in Fig. 19(a) - (b) and Table 4 that for flat body phantom only small amount of power is absorbed by the body, showing that the conductive ground plane is sufficient for shielding the human body. Due to the close coupling of lossy human body and bending of conventional antenna around it, most of the power is absorbed in the body which gives a high value of SAR, averaged over $10 \mathrm{~g}$ of tissue, as shown in Fig. 19(c) - (d).

The metamaterial inspired antenna dramatically reduces the value of SAR. This is due to HIS behavior of meta- 
material surface using as a ground plane, which provide a surface wave band gap at the desired frequency. This surface provide electromagnetic insulation of an antenna from the body. Therefore, a controlled SAR value had been obtained below the safe level $(<2 \mathrm{~W} / \mathrm{kg}$ (ICNIRP standard)). The SAR of the proposed antenna is reduced by $69 \%$ and $83.82 \%$ using a $5 \times 5$ Vialess and with-via EBG ground plane, respectively, relative to the conventional antenna, as shown in Fig. 19(e) - (f).

\section{Conclusion}

In this paper the design and specific absorption rate analysis of a $2.4 \mathrm{GHz}$ wearable microstrip patch antenna on a conventional and electromagnetic bandgap (EBG) ground planes under normal and bent conditions has been discussed. For flexibility and conformability purposes, wearable materials have been used in the design of the antenna as well as EBG surfaces. Therefore the proposed antenna is a suitable candidate for body worn applications. The overall volume of the proposed antenna is $113 \times 96.4 \mathrm{x}$ $3 \mathrm{~mm}^{3}$. The metamaterial surface has been used as a high impedance surface which protects the body from the hazards of electromagnetic radiations. Due to the surface wave suppression capability of the EBG, the efficiency of an antenna has been increased from 52 to $74 \%$. In addition due to the EBG ground plane, the $3 \mathrm{~dB}$ beamwidth of the antenna is enhanced from $65^{\circ}$ to $95^{\circ}$, thereby increasing the angular coverage range of it. Relatively safer value of SAR (i.e. $1.77 \mathrm{~W} / \mathrm{kg}<2 \mathrm{Wkg}$ ) has been achieved when the EBG (with via) based antenna has been worn on human body. It has been found that the SAR has been abridged by $83.82 \%$ as compare to the conventional antenna $(8.16 \mathrm{~W} / \mathrm{kg}>2 \mathrm{~W} / \mathrm{kg})$. Due to the lossy nature of the human body the gain and efficiency of the conventional antenna has been reduced under flat as well as bent conditions. It is worth mentioning that the $\mathrm{E}$ and $\mathrm{H}$ plane gain of the EBG based antenna is minimally affected under bent conditions. The proposed antenna can be potentially used in wearable electronics, sports, rescue, military, communication, and smart clothing applications, in Industrial, Scientific and Medical (ISM) band. Prototypes of the antennas will be fabricated to validate the numerical results.

\section{Acknowledgements}

The authors of the manuscript thankfully acknowledge CST and Loughborough University for their support in the numerical analysis of the proposed work.

\section{References}

[1] P. S. Hall, and Y. Hao, “Antennas and propagation for body centric communications," 2006 First European Conference (EuCAP) on Antennas and Propagation, pp. 1-7, DOI 10.1109/EUCAP.2006.4584864

[2] A. S. M. Alqadami, and M. F. Jamlos, "Design and development of a flexible and elastic UWB wearable antenna on PDMS substrate," 2014 In Asia-Pacific Conference on Applied Electromagnetics (APACE), pp. 27-30, DOI 10.1109/APACE.2014.7043799

[3] S. Gao, S. Xiao, D. Jin, and B. Z. Wang, "Wideband antenna for ultra-wideband (UWB) body-centric wireless communications," 2010 In International Conference on Ultra-Wideband (ICUWB), Vol. 1, pp. 1-4, DOI 10.1109/ICUWB.2010.5614291

[4] I. Locher, M. Klemm, T. Kirstein, and G. Troster, "Design and characterization of purely textile patch antennas," IEEE Trans. on Advanced Packaging., Vol. 29, no. 4, pp.777-788, Nov.2006.

[5] R. Bharadwaj, S. Swaisaenyakorn, C. Parini, J. Batchelor, and A. Alomainy, "Motion tracking of a human subject in healthcare applications using compact ultra wideband antennas," 2014 Fourth International Conference on Wireless Mobile Communication and Healthcare (Mobihealth), pp. 199202, DOI 10.1109/MOBIHEALTH.2014.7015945

[6] A. Jharesh, P. P. Priya, S. D. Murali, P. Hariharnath, and V. P.K. Naga Sai, "Performance Evaluation of Dual Band E - Shaped Microstrip Patch Antenna on Different Textiles for Wearable Applications in L \& S Bands," Journal of Basic and Applied Sciences, Vol. 9, no. 2, pp. 260-268, 2015.

[7] Y. H. Chen, and H. T. Lin, "Dual-band frequency selective surface for improving the transmission of Bluetooth and WLAN signals through an energysaving glass," Journal of the Chinese Institute of Engineers, pp.1-6, 2015.

[8] S. Zhang, A. Chauraya, W. Whittow, R. Seager, T. Acti, T. Dias, T. and Y. Vardaxoglou, "Embroidered wearable antennas using conductive threads with different stitch spacing," 2012 Loughborough Antennas and Propagation Conference (LAPC), pp. 1-4, DOI 10.1109/USNC-URSI.2013.6715521

[9] S. Zhu, and R. Langley, "Dual-band wearable textile antenna on an EBG substrate," IEEE Trans. on Antennas and Propagation., Vol. 57, no. 4, pp. 926935, Apr. 2009.

[10] B. Sanz-Izquierdo, F. Huang, C. J. Batchelor, and M. Sobhy, "Compact antenna for WLAN on body applications," 2006 Thirty-sixth European Microwave Conference, pp. 815-818, DOI10.1109/EUMC.2006. 281044

[11] K. S. Mishra, S. Shukla, and V. Mishra, "Design of dual band textile antenna for ISM bands using fractal geometry," 2015 International Conference on Signal Processing and Communication (ICSC), pp. 161-165, DOI 10.1109/ICSPCom.2015.7150640

[12] S. Sankaralingam, and B. Gupta, "Use of electro- 
textiles for development of wibro antennas," Progress In Electromagnetics Research C, Vol. 16, pp. 183-193, 2010.

[13] A. E. Kaur, H. E. Malik, V. E. Tanwar, K. V. Lamba, N. E. Kumar, and S. Sharma, "Effect of Permittivity and Conductivity of Tissue on Specific Absorption Rate of Electromagnetic Radiations," International Journal of Innovative technology and Exploring Engineering (IJITEE), Vol. 1, no. 6, pp. 20-22, 2012.

[14] T. M. Islam, Z. H. Abidin, I. R. M. Faruque, and N. Misran, "Analysis of materials effects on radio frequency electromagnetic fields in human head," Progress In Electromagnetics Research, Vol. 128, pp. 121-136.

[15] A. Afridi, S. Ullah, S. Khan, A. Ahmed, A. H. Khalil, M. A. Tarar, "Design of Dual Band Wearable Antenna Using Metamaterials," Journal of Microwave Power and Electromagnetic Energy, Vol. 47, no. 2, pp. 126137, 2013.

[16] D. D. Arumugam, W.D Engels, and M.H. Mickle, "Specific absorption rates in muscle tissues for passive UHF RFID tag backscatter," IEEE Radio and Wireless Symp, Vol. 09, pp. 445-448, January 2009.

[17] W.A.N.G. Jianqing, and O. Fujiwara, "Reduction of electromagnetic absorption in the human head for portable telephones by a ferrite sheet attachment," IEICE Trans. on Communications, Vol. 80, no. 12, pp. 1810-1815, Dec. 1997.

[18] H. K. Chan, M. K. Chow, L. C. Fung, and S. W. Leung, "Effects of using conductive materials for SAR reduction in mobile phones," Microwave and optical technology letters, Vol. 44, no. 2, pp. 140-144, Jan. 2005.

[19] E. Ozbay, K. Aydin, E. Cubukcu, and M. Bayindir, "Transmission and reflection properties of composite double negative metamaterials in free space," IEEE Trans. on antennas and propagation, Vol. 51, no. 10, pp. 2592-2595, Oct. 2003.

[20] D. Shi, Y. Gao, and X. Lu, "SAR reduction on a GSM terminal with EBG structure," 2012 sixth AsiaPacific Conference on Environmental Electromagnetics (CEEM), pp. 333-336, DOI 10.1109/CEEM.2012. 6410636

[21] C. A. Balanis (Editor), Antenna theory: analysis and design, John Wiley and Sons, 2006.

[22] A. G. Derneryd, "A theoretical investigation of the rectangular microstrip antenna element," IEEE Trans. on Antennas and Propagation, Vol. 26, no. 4, pp. 532-535, Jul. 1978.

[23] Y. Rahmat-Samii, and H. Mosallaei, "Electromagnetic band-gap structures: classification, characterization, and applications," 2001 International Conference on Antennas and Propagation, pp. 560-564, DOI10.1049/ cp: 20010350

[24] D. Sievenpiper, L. Zhang, J. F. R. Broas, G. N. Alexopolous, and E. Yablonovitch, "High-impedance electromagnetic surfaces with a forbidden frequency band," IEEE Trans. on Microwave Theory and Techniques, Vol. 47, no. 11, pp. 2059-2074, Nov. 1999.

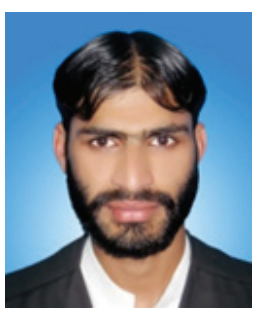

Usman Ali is a postgraduate research student in the Department of Telecommunication Engineering, University of Engineering and Technology (UET) Peshawar. He did his Bachelors from UET Peshawar in 2012. His research interests include metamaterials, signal processing, electromagnetic Bandgap structures and wearable antennas. Currently he is working as a Lab Engineer in the same Department.

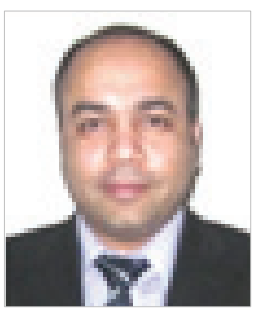

Sadiq Ullah is Head of the Telecommunication Engineering Department, University of Engineering \& Technology, Peshawar, Pakistan. He received B.Sc. Electrical Engineering from University of Engineering and Technology, Peshawar, Pakistan. He achieved his M.Sc. in Electrical Engineering from University of Engineering and Technology Taxila, Pakistan. In 2007, he joined the Department of Electronic and Electrical Engineering, at Loughborough University, U.K., and was awarded Ph.D. for his research in the field of design and measurement of metamaterial based antennas in 2010. He worked as an Assistant Manager (Electronics) in a public sector R \& D organization in Islamabad, where his main responsibilities were hardware, software co-design, designing and testing of high precession electronics, test equipment. His research mainly focuses on design and measurement of low-profile antennas, metamaterials, RFID $\&$ reconfigurable antennas, $5 \mathrm{G}$ antennas, SAR analysis of implantable and wearable antennas. He has been worked as a Research Associate at Loughborough University, where he researched on the propagation effects of rain, snow, ice, fog and forest in millimeter wave band. He published his research in international conferences and journals.

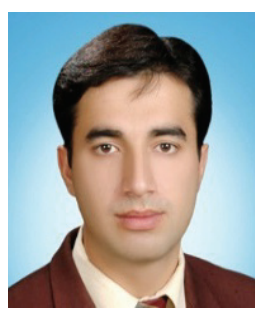

Jalal Khan is Assistant Professor at the Department of Telecommunication Engineering, University of Engineering \& Technology, Peshawar, Pakistan. He received B.Sc. Electrical Engineering from University of Engineering and Technology, Peshawar, Pakistan. He achieved his M.Sc. from Bradford University, UK. Currently he is pursuing his $\mathrm{PhD}$ in $5 \mathrm{G}$ antennas in Telecommunication Engineering, in UET Peshawar, Pakistan. 


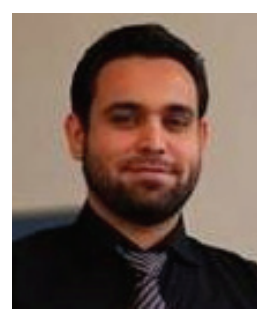

Muhammad Shafi is currently working as associate professor at Computer Science Department, Islamic University Madinah, Saudi Arabia. He did his $\mathrm{PhD}$ from Loughborough University, UK in 2010 and since then he has been involved in teaching and research. His research interests include, image processing, communication and antennas.

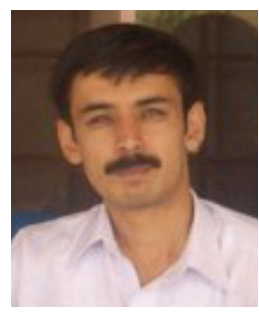

Babar Kamal, is currently a $\mathrm{PhD}$ student in School of Marine Science and Technology, NPU, China. He did his Bachelors from BUITEMS, Quetta in 2012 and Masters from Telecommunication Engineering Department, UET Peshawar in 2015. His research interests include metamaterials, and wearable antennas.

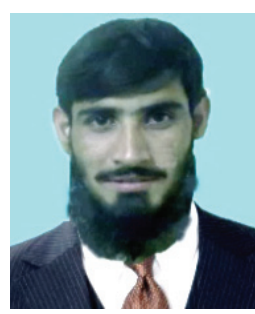

Abdul Basir is currently doing MSc leading to $\mathrm{PhD}$ in Ulsan University, South Korea. He received B.Sc. Telecommunication Engineering from University of Engineering and Technology, Peshawar, Pakistan in 2015. Currently he is working on design and analysis of implantable and wearable

antennas.

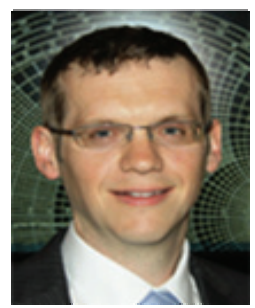

James A Flint is Senior Lecturer in Wireless Systems Engineering and Head of the Communications Research Division within the School. His research focuses on various aspects of wireless systems, especially in the area of transducer design in electromagnetic and acoustics. He has a keen interest in biomimetics, ultrasound and on converting systems found in nature into workable engineering solutions. Dr Flint was previously employed in the automotive industry and maintains an interest in safety-critical systems, installed performance of antennas and electromagnetic compatibility. In recent years Dr Flint has had a particular interest in band gap structures (both electromagnetic and acoustic) and has several publications in the area. Dr Flint's external activities include acting as an elected representative on the Council of the Institution of Engineering and Technology.

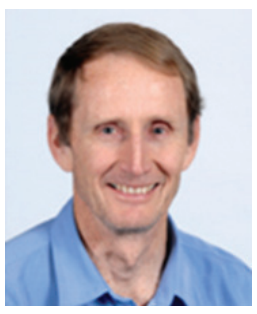

Rob D Seager was born in Botswana and schooled in Africa, Rob studied Electronics at Bangor University in Wales, before working with Hewlett Packard Ltd in Scotland. After Postgraduate studies in Bangor he moved to Loughborough University and is working as a Senior Lecturer in

Communications Division. His current research interests are switched antenna systems, polarization dependent surfaces, propagation control within buildings, antennas, tunable and switchable microwave filters, fabric antennas and systems and frequency selective surfaces 